\title{
BMJ Open Frequency of television viewing and association with overweight and obesity among women of the reproductive age group in Myanmar: results from a nationwide cross-sectional survey
}

$\overline{\text { Rajat Das Gupta, }{ }^{\oplus 1,2} \text { Ibrahim Hossain Sajal, }{ }^{2} \text { Mehedi Hasan, }{ }^{\odot 1,2} \text { Ipsita Sutradhar, }{ }^{1,2}}$ Mohammad Rifat Haider, ${ }^{3,4}$ Malabika Sarker ${ }^{1,2,5}$

To cite: Das Gupta R, Sajal IH, Hasan M, et al. Frequency of television viewing and association with overweight and obesity among women of the reproductive age group in Myanmar: results from a nationwide crosssectional survey. BMJ Open 2019;9:e024680. doi:10.1136/ bmjopen-2018-024680

- Prepublication history and additional material for this paper are available online. To view please visit the journal online (http://dx.doi.org/10.1136/ bmjopen-2018-024680).

$\mathrm{RDG}, \mathrm{IHS}, \mathrm{MH}$ and IS contributed equally.

Received 8 June 2018 Revised 4 February 2019 Accepted 12 February 2019
Check for updates

(C) Author(s) (or their employer(s)) 2019. Re-use permitted under CC BY-NC. No commercial re-use. See rights and permissions. Published by BMJ.

For numbered affiliations see end of article.

Correspondence to Dr Rajat Das Gupta; rajat89.dasgupta@gmail.com

\section{ABSTRACT}

Objectives This study aimed to discern the association between the frequency of television viewing and overweight and obesity among reproductive age women of Myanmar.

Design This was a cross-sectional study.

Setting This study used Myanmar Demographic and Health Survey (2015-2016) data.

Participants Total of 12021 women both aged 15-49 years and also not pregnant or did not deliver a child within the 2 months prior to the survey were included. Primary and secondary outcome measures The primary outcome was overweight $\left(23.0 \mathrm{~kg} / \mathrm{m}^{2}\right.$ to $<27.5 \mathrm{~kg} /$ $\left.\mathrm{m}^{2}\right)$ and obesity $\left(\geq 27.5 \mathrm{~kg} / \mathrm{m}^{2}\right)$, which was measured using the Asian body mass index cut-off. Ordered logistic regression analysis was conducted to find the association between the explanatory and outcome variables. The potential confounders controlled in the multivariable analyses were age, place of residence, region of residence, highest educational status, current employment status, wealth index, parity and number of household members. Results The prevalence of overweight was $26.5 \%$ and obesity was $12.2 \%$ among the study participants. The odds of being overweight and obese were $20 \%$ higher (adjusted OR (AOR) 1.16, 95\% Cl 1.02 to 1.32; $\mathrm{p}=0.023$ ) among those who watched television at least once a week compared with those who did not watch television at all. Rural women who watched television at least once a week were 1.2 times more likely to be obese (AOR $1.16,95 \% \mathrm{Cl}$ 1.01 to $1.34 ; p=0.040$ ) compared with those who did not watch television at all.

Conclusions Frequent television watching was associated with obesity among rural women of reproductive age in Myanmar.

\section{INTRODUCTION}

Both developed and developing countries are facing the increasing burden of overweight and obesity, which are posing major public health problems. ${ }^{1-3}$ The prevalence of overweight and obesity increased by $27.5 \%$ among the global adult population and $47.1 \%$ among

\section{Strengths and limitations of the study}

- This study used a nationally representative sample to investigate the association between the frequency of television viewing and overweight/obesity among women of reproductive age from Myanmar.

- Due to utilisation of standard and valid tools for data collection, the probability of the existence of measurement error is lower in this study in comparison to other cross-sectional studies conducted in Myanmar.

- Temporal relationship could not be established due to the cross-sectional nature of the survey.

- The frequency of television viewing was measured in weeks, not in days/hours; the latter could have given more precise information.

- In the multivariable analysis, food habits and duration of physical activity were not included because that information was not collected in the survey.

the global child population between 1980 and 2013. ${ }^{4}$ During the same time period, globally, the prevalence of overweight and obesity rose from $29.8 \%$ to $38.0 \%$ among adult women, in particular. ${ }^{4}$ Although this burden is lowest in South and South-East Asia, countries of this region are still experiencing the rising burden of overweight and obesity. ${ }^{5}$ Myanmar is a low and middle-income country situated in the South-East Asia region. In 2015-2016, the first Myanmar Demographic and Health Survey (MDHS) was conducted using a nationally representative sample across the country. ${ }^{6}$ The survey found a high prevalence of overweight and obesity among women of reproductive age. ${ }^{7}$

Overweight and obesity is an important risk factor for the development of several non-communicable diseases (NCDs) like diabetes mellitus, ${ }^{8}$ hypertension, ${ }^{9}$ 
cardiovascular diseases, ${ }^{10}$ cancer $^{11}$ and chronic kidney diseases. ${ }^{12}$ In addition, overweight and obese women experience complications during pregnancy (gestational diabetes mellitus, pre-eclampsia and eclampsia) more frequently than women of normal body weight. ${ }^{13} 14$

It has been found that energy expenditure is very low among people who spend their leisure time watching television, rather than being involved in physical activities like playing games, gardening, and so on. This ultimately increases their risk of gaining excessive body weight. ${ }^{1516}$ Television watching is also associated with an increase in energy intake, which may sometimes be attributable to their frequent exposure to television advertisements of food and beverages and the subsequent consumption of the said food and beverages. ${ }^{17-21}$

Across the world, many studies have shown a positive association between the increased frequency of television viewing and overweight/obesity. In the USA and Australia, it has been found that people who view television more frequently are at higher risk of being overweight/obese. ${ }^{20}{ }^{22-24} \mathrm{~A}$ study from Bangladesh has found that watching television frequently (at least once a week) was associated with obesity among women of reproductive age.$^{25}$ However, this association has not been explored in other South and South-East Asian countries including Myanmar. Therefore, this study was conducted to determine the association between television viewing and the prevalence of overweight and obesity among women of reproductive age in Myanmar using the MDHS 20152016 data.

\section{METHODS}

\section{Study settings}

According to the 2014 census, the total population of Myanmar was 51.5 million with a population density of 76 persons per square kilometre $\left(\mathrm{km}^{2}\right)$. The country is home to 135 ethnic groups. ${ }^{26}{ }^{27}$ The gross domestic product growth rate of Myanmar was $6.4 \%$ and per capita, gross national income was US\$1455 in 2016-2017. More than a quarter $(26.1 \%)$ of the population was living under the poverty line in 2014. Myanmar also has the lowest life expectancy at birth (66.6 years) among the Association of Southeast Asian Nations. ${ }^{26} 28$

\section{Study design}

This study analysed the data of MDHS 2015-2016, the first demographic and health survey of Myanmar. ${ }^{6}$ The detailed method has been published previously. ${ }^{6}$ MDHS 2015-2016 was a cross-sectional survey which used a nationally representative sample and was conducted through a joint collaboration between the Ministry of Health and Sports of Myanmar and ICF International. The US Agency for International Development and the Three Millennium Development Goals fund provided financial support for the survey. Two-stage cluster sampling techniques were used for

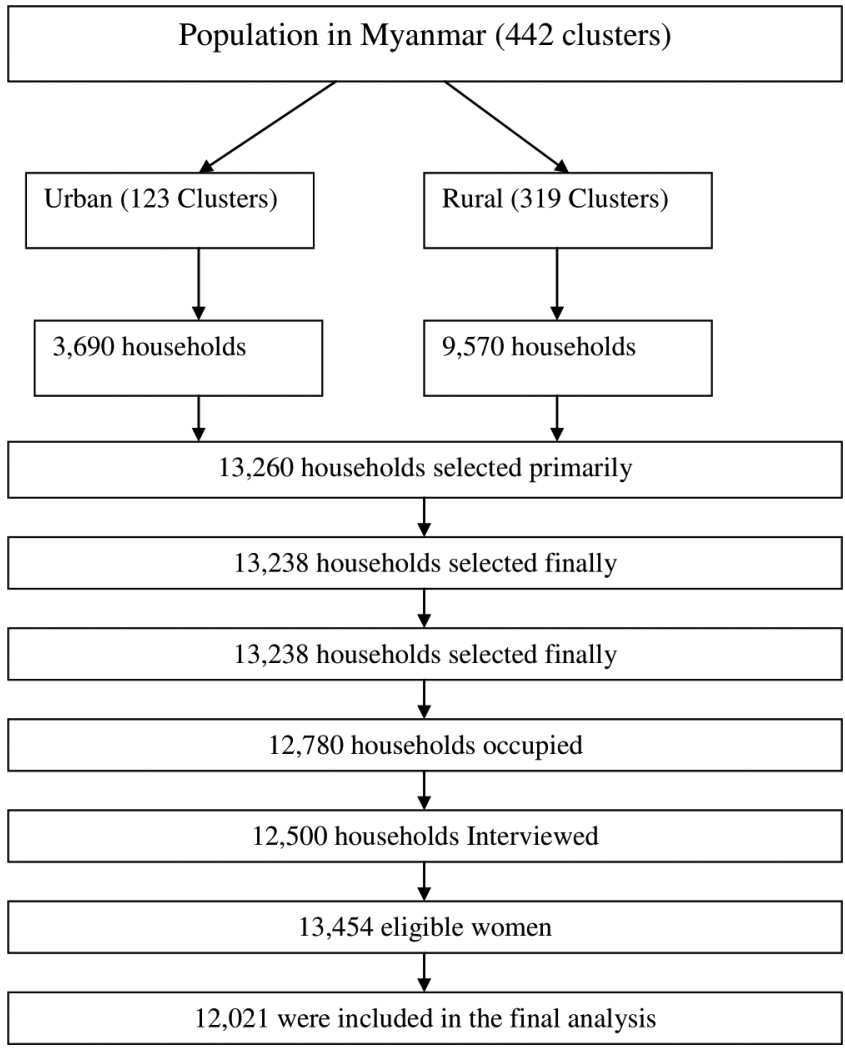

Figure 1 Flow chart showing the process of selecting the participants in the survey.

sample selection. The sample was stratified for each of the seven states and eight regions of Myanmar. At the first stage, 442 clusters (urban: 123 and rural: 319) were selected randomly from a sample frame of 4000 clusters. At the second stage, 30 households were selected from each of the clusters. In total, 13260 households were selected for the final sample. The target group of this study was women of reproductive age (15-49 years). The permanent residents and the visitors who stayed in the selected households the night before the date of data collection were included in the questionnaire survey. Around $96 \%$ of eligible women agreed to participate in the survey. Among them, $98 \%$ agreed for anthropometric measurement. However, pregnant women and women who had given birth within the preceding 2 months of the survey were excluded. The final weighted sample size of this study was 12021 (figure 1).

\section{Survey tools and data collection}

A standard woman's questionnaire used by the DHS programme was adopted and modified according to the local context and pretested to collect sociodemographic information (eg, age, sex, household wealth index and place of residence) through face-to-face interviews. Trained field staff carried out the interviews and anthropometric measurements. Measuring boards specially made by Shorr Productions were used for height measurement and lightweight SECA scales with 
digital screens were used for measuring the weight of the respondents.

The main outcome variables of this study were overweight and obesity. To define these variables, an Asia specific body mass index (BMI) cut-off value was used. ${ }^{29}$ Women having a BMI $<23.0 \mathrm{~kg} / \mathrm{m}^{2}$ were considered to be normal weight or underweight, women having a BMI between $23.0 \mathrm{~kg} / \mathrm{m}^{2}$ and $<27.5 \mathrm{~kg} / \mathrm{m}^{2}$ were considered to be overweight and women having a BMI $\geq 27.5 \mathrm{~kg} / \mathrm{m}^{2}$ were considered to be obese.

The main explanatory variable of interest for this study was the frequency of viewing television. Data were collected as the following categories: (1) Not viewing television at all. (2) Viewing television less than once a week. (3) Viewing television at least once a week. ${ }^{10}$ The other independent variables considered based on the literature review were age group, place of residence, region of residence, education, wealth quintile, current working status, parity and number of household members in the family. The categories of the variables are mentioned in table 1 .

\section{Data analysis}

Weighted descriptive statistics (frequency and percentage) were used to present the sociodemographic characteristics of the respondents. A $\chi^{2}$ test was performed to determine whether the groups differed in terms of the explanatory variables according to the BMI status. To find the association between the explanatory and outcome variables, ordered logistic regression analysis was conducted considering the proportional odds assumption was fulfilled. Initially, bivariate analyses were done. Variables which showed a p value $<0.20$ in bivariate analyses were included in the multivariable model. This value of 0.2 was considered statistically significant to prevent residual confounding in multivariable analysis. ${ }^{30}$ The variables which showed $\mathrm{p}<0.05$ in multivariable analyses were considered to be statistically significant. Both the unadjusted crude OR and adjusted OR (AOR) were reported. Variance inflation factors (VIF) were assessed to check multicollinearity among the variables. A VIF value greater than 5 was considered as an indication of multicollinearity; however, no significant multicollinearity was observed. ${ }^{31} \mathrm{~A}$ test for interaction effect between the frequency of TV viewing and the place of residence was performed; however, no significant interaction effect was observed. The cluster effect was adjusted during analysis. All the analyses were done using Stata V.13.0. The authors followed the guidelines outlined in the Strengthening the Reporting of Observational Studies in Epidemiology statement in writing the manuscript (online supplementary file 1).

\section{Ethical consideration}

Written informed consent was taken from the participants. In case of minor participants, assent form was signed by the respondents and written informed consent was given by the adult guardian.
Table 1 List of variables considered for the study

\begin{tabular}{|c|c|}
\hline Name of the variables & Categories \\
\hline \multicolumn{2}{|l|}{ Outcome variables } \\
\hline $\begin{array}{l}\text { Body mass index } \\
\text { (BMI) }\end{array}$ & $\begin{array}{l}\text { a. } 0=\text { Normal weight or underweight } \\
\left(B M l<23 \mathrm{~kg} / \mathrm{m}^{2}\right) \\
\text { b. } 1=\text { Overweight }\left(\mathrm{BMI} 23.0 \mathrm{~kg} / \mathrm{m}^{2}\right. \\
\left.\text { to }<27.5 \mathrm{~kg} / \mathrm{m}^{2}\right) \\
\text { c. } 2=\text { Obesity }\left(\mathrm{BMl} \geq 27.5 \mathrm{~kg} / \mathrm{m}^{2}\right)\end{array}$ \\
\hline \multicolumn{2}{|l|}{ Explanatory variable } \\
\hline $\begin{array}{l}\text { Frequency of viewing } \\
\text { television }\end{array}$ & $\begin{array}{l}\text { a. } 0=\text { Notat all } \\
\text { b. } 1=\text { Less than once a week } \\
\text { c. } 2=\text { At least once a week }\end{array}$ \\
\hline \multicolumn{2}{|l|}{ Covariates } \\
\hline 1. Age groups & $\begin{array}{l}\text { a. } 0=15-24 \text { years } \\
\text { b. } 1=25-34 \text { years } \\
\text { c. } 2=35-49 \text { years }\end{array}$ \\
\hline 2. Place of residence & $\begin{array}{l}\text { a. } 0=\text { Urban } \\
\text { b. } 1=\text { Rural }\end{array}$ \\
\hline $\begin{array}{l}\text { 3. Region of } \\
\text { residence }\end{array}$ & $\begin{array}{l}\text { a. } 0=\text { Kachin } \\
\text { b. } 1=\text { Kayah } \\
\text { c. } 2=\text { =ayin } \\
\text { d. } 3=\text { =hin } \\
\text { e. } 4=\text { Sagaing } \\
\text { f. } 5=\text { Taninthayi } \\
\text { g. } 6=\text { Bago } \\
\text { h. } 7=\text { =agway } \\
\text { i. } 8=\text { Mandalay } \\
\text { j. 9=Mon } \\
\text { k. 10=Rakhine } \\
\text { I. 11=Yangon } \\
\text { m. 12=Shan } \\
\text { n. 13=Ayeyarwaddy } \\
\text { o. 14=Naypyitaw }\end{array}$ \\
\hline 4. Education & $\begin{array}{l}\text { a. } 0=\text { No education } \\
\text { b. } 1=\text { Primary education } \\
\text { c. } 2=\text { Secondary education } \\
\text { d. } 3=\text { Higher education }\end{array}$ \\
\hline 5. Wealth quintile & $\begin{array}{l}\text { a. } 0=\text { Poorest } \\
\text { b. } 1=\text { Poorer } \\
\text { c. } 2=\text { Middle } \\
\text { d. } 3=\text { Richer } \\
\text { e. } 4=\text { Richest }\end{array}$ \\
\hline $\begin{array}{l}\text { 6. Current working } \\
\text { status }\end{array}$ & $\begin{array}{l}\text { a. } 0=\text { Yes } \\
\text { b. } 1=\text { No }\end{array}$ \\
\hline 7. Parity & $\begin{array}{l}\text { a. } 0=0 \text { (nullipara) } \\
\text { b. } 1=1 \text { (primipara) } \\
\text { c. } 2=2 \\
\text { d. } 3=3 \\
\text { e. } 4=>3\end{array}$ \\
\hline $\begin{array}{l}\text { 8. Number of } \\
\text { household members }\end{array}$ & $\begin{array}{l}\text { a. } 0=\leq 5 \\
\text { b. } 1=>5\end{array}$ \\
\hline
\end{tabular}

\section{Patient involvement}

Patients were not involved in the study.

\section{FINDINGS}

\section{Sociodemographic characteristics of the respondents}

The data of 12021 weighted samples were analysed. More than a quarter $(26.5 \%)$ of the study participants were overweight, and $12.2 \%$ of them were obese (figure 2). The sociodemographic characteristics of 


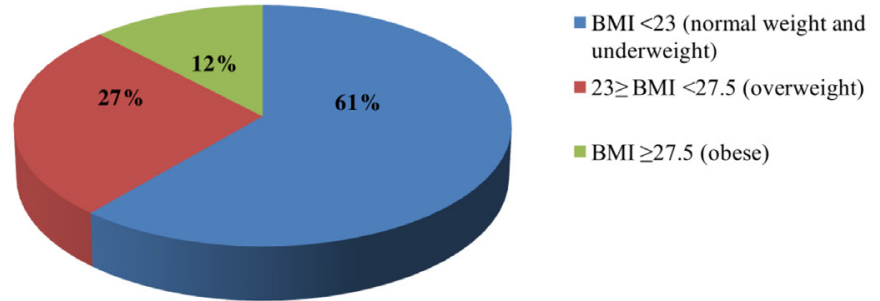

Figure 2 Distribution of the respondents by body mass index (BMI) status.

the respondents along with the prevalence of the three categories of BMI across the independent variables with the associated $\chi^{2}$ value are presented in table 2 . The majority of the study participants was aged between 35 years and 49 years $(42.3 \%)$ and was residing in rural areas $(70.8 \%)$. The highest proportion of participants was from the Yangon region $(15.1 \%)$, followed by the Ayeyarwaddy region $(12.5 \%)$ and the Mandalay region (12.2\%), whereas the lowest participation was from the Kayah region $(0.5 \%)$. Around half of the respondents $(41.3 \%)$ were educated up to the primary level and about a third $(36.1 \%)$ received secondary level education; furthermore, $10.2 \%$ received higher education and $12.4 \%$ received no education. More than two-thirds $(68.1 \%)$ of the women were employed at the time of interview. Nearly two-fifths of the women $(41.7 \%)$ were nulliparous, while cumulatively a similar proportion of respondents $(46.6 \%)$ had the experience of being pregnant-once $(15.3 \%)$, twice $(15.8 \%)$, thrice $(11.7 \%)$ and more than three times $(15.5 \%)$. The highest proportion of the respondents belonged to the richest wealth quintile $(22.2 \%)$ followed by richer $(21.1 \%)$ and middle $(20.9 \%)$ quintiles. Among the study participants, the majority $(60.1 \%)$ reported that they watched television at least once a week; however, $23.1 \%$ did not watch television at all and $16.8 \%$ watched television less than once a week. Except for current employment status, significant differences were found among the BMI of women across the explanatory variables. The prevalence of overweight and obesity increased with age $(\mathrm{p}<0.0001)$ and was most common in the Yangon and Kachin regions $(\mathrm{p}<0.0001)$. This prevalence was also higher in the urban areas compared with the rural areas (overweight: $31.1 \%$ vs $24.6 \%$; obesity: $17.9 \%$ vs $9.8 \%$; $\mathrm{p}<0.0001)$. Plausibly, women with higher educational status, having two children and belonging to the richest wealth group had a higher prevalence of overweight and obesity $(p<0.0001)$. The prevalence of overweight and obesity was also higher among the individuals who used to watch television at least once a week $(\mathrm{p}<0.0001)$ (table 2$)$.

The frequency of watching television at least once a week was higher among the urban than the rural women ( $80.8 \%$ vs $51.7 \%$ ). Around $30 \%$ of the rural women did not view television at all, whereas the proportion was lower for the urban women (7.2\%) (figure 3).
Association between the frequency of viewing television and overweight and obesity

Ordered logistic regression was used to discern the association between frequency of viewing television and overweight and obesity. During the analyses, the normal weight category (BMI $<23 \mathrm{~kg} / \mathrm{m}^{2}$ ) was held as the reference group. The results are presented in table 3 . In the final model after adjusting for age, place and region of residence, wealth index, highest educational status, current employment status, parity and number of household members, it was found that women who watched television at least once a week were 1.2 times more likely to be overweight and obese than women who never watched television (AOR 1.16, 95\% CI 1.02 to 1.32 ; $\mathrm{p}=0.023$ ).

When stratified by urban and rural residence, overweight and obesity showed significant association with the frequency of viewing television in the urban areas. However, in the rural areas, women who watched television at least once a week were 1.2 times more likely to be overweight and obese than those who did not watch television at all (AOR 1.16, 95\% CI 1.01 to $1.34 ; \mathrm{p}=0.040$ ) (table 3).

The final logistic regression models are shown in online supplementary tables 1-3 (supplementary file 2).

\section{Model goodness-of-fit}

To assess the internal validity of the regression model, the F-adjusted mean residual goodness-of-fit test was used. The $p$-value of the F statistics of the adjusted model was $<0.001$, indicating an acceptable model fitness.

\section{DISCUSSION}

To the best of our knowledge, this is the first study to use a nationally representative sample to examine the association between frequency of television viewing with the prevalence of overweight and obesity among women of reproductive age in Myanmar. More than a fourth of the women surveyed were overweight and one in eight women was obese. This study also found that watching television at least once a week was significantly associated with overweight/obesity in women of reproductive age in rural Myanmar.

The prevalence of overweight and obesity among women of reproductive age was found to be $26.5 \%$ and $12.2 \%$, respectively. The total burden of overweight/ obesity $(38.7 \%)$ was almost similar to the burden of overweight and obesity among the same target group in other South and South-East Asian countries, including Nepal $(32.8 \%),{ }^{32}$ Bangladesh $(36 \%)^{3}$ and Pakistan $(39 \%){ }^{33}$ Each of these studies used a nationally representative sample and the Asian BMI cut-off.

The prevalence of overweight and obesity was higher among the women living in the urban areas compared with those living in the rural areas. This finding is consistent with studies done in other South and South-East Asian countries, including Bangladesh, as well as in the other continents. ${ }^{325} 34-36$ Urban women had a higher 
Table 2 Sociodemographic characteristics of the study participants and prevalence of overweight and obesity across the independent variables, MDHS 2015-2016 $(n=12021)$

\begin{tabular}{|c|c|c|c|c|c|c|}
\hline \multirow[b]{2}{*}{ Variable } & \multirow[b]{2}{*}{ Frequency (\%) } & \multicolumn{3}{|c|}{ Body mass index (BMI) status (\%) } & \multirow[b]{2}{*}{$\chi^{2}$} & \multirow[b]{2}{*}{$P$ value } \\
\hline & & $\mathrm{BMI}<23 \mathrm{~kg} / \mathrm{m}^{2}$ & $\begin{array}{l}23 \mathrm{~kg} / \mathrm{m}^{2} \geq \mathrm{BMI} \\
<27.5 \mathrm{~kg} / \mathrm{m}^{2}\end{array}$ & $\mathrm{BMI} \geq 27.5 \mathrm{~kg} / \mathrm{m}^{2}$ & & \\
\hline \multicolumn{7}{|l|}{ Age group (years) } \\
\hline $15-24$ & $3433(28.6)$ & 82.4 & 14.3 & 3.3 & \multirow[t]{3}{*}{173.9} & \multirow[t]{3}{*}{$<0.0001^{\star}$} \\
\hline $25-34$ & $3504(29.1)$ & 60.4 & 27.6 & 12.0 & & \\
\hline $35-49$ & $5084(42.3)$ & 47.7 & 34.0 & 18.3 & & \\
\hline \multicolumn{7}{|l|}{ Place of residence } \\
\hline Urban & 3505 (29.2) & 51.0 & 31.1 & 17.9 & \multirow[t]{2}{*}{258.4} & \multirow[t]{2}{*}{$<0.0001 *$} \\
\hline Rural & $8516(70.8)$ & 65.6 & 24.6 & 9.8 & & \\
\hline \multicolumn{7}{|l|}{ Region of residence } \\
\hline Kachin & $334(2.8)$ & 54.6 & 30.0 & 15.4 & \multirow[t]{15}{*}{240.1} & \multirow[t]{15}{*}{$<0.0001^{\star}$} \\
\hline Kayah & $60(0.5)$ & 63.3 & 27.1 & 9.6 & & \\
\hline Kayin & $274(2.3)$ & 59.1 & 27.1 & 13.8 & & \\
\hline Chin & $90(0.8)$ & 71.7 & 23.9 & 4.4 & & \\
\hline Sagaing & 1351 (11.3) & 58.7 & 27.7 & 13.6 & & \\
\hline Taninthayi & $265(2.2)$ & 57.0 & 28.6 & 14.4 & & \\
\hline Bago & $1197(9.9)$ & 64.5 & 25.9 & 9.6 & & \\
\hline Magway & $1030(8.6)$ & 67.7 & 24.0 & 8.3 & & \\
\hline Mandalay & $1462(12.2)$ & 64.2 & 25.4 & 10.5 & & \\
\hline Mon & $432(3.6)$ & 59.7 & 25.0 & 15.3 & & \\
\hline Rakhine & $695(5.8)$ & 75.3 & 19.2 & 5.5 & & \\
\hline Yangon & $1822(15.1)$ & 49.7 & 33.8 & 16.5 & & \\
\hline Shan & $1216(10.1)$ & 60.2 & 25.7 & 14.1 & & \\
\hline Ayeyarwaddy & $1508(12.5)$ & 64.8 & 23.3 & 11.8 & & \\
\hline Naypyitaw & $285(2.3)$ & 63.3 & 26.0 & 10.7 & & \\
\hline \multicolumn{7}{|l|}{ Highest educational status } \\
\hline No formal education & 1485 (12.4) & 65.4 & 25.3 & 9.3 & \multirow[t]{4}{*}{40.5} & \multirow[t]{4}{*}{$0.0003^{*}$} \\
\hline Primary & 4966 (41.3) & 59.8 & 27.6 & 12.6 & & \\
\hline Secondary & $4345(36.1)$ & 63.1 & 25.3 & 11.6 & & \\
\hline Higher & $1225(10.2)$ & 56.6 & 28.1 & 15.3 & & \\
\hline \multicolumn{7}{|l|}{ Currently employed } \\
\hline Yes & $8184(68.1)$ & 61.2 & 26.6 & 12.2 & \multirow[t]{2}{*}{0.2} & \multirow[t]{2}{*}{0.9348} \\
\hline No & 3837 (32.9) & 61.6 & 26.4 & 12.0 & & \\
\hline \multicolumn{7}{|l|}{ Wealth index } \\
\hline Poorest & $2052(17.1)$ & 75.2 & 18.6 & 6.2 & \multirow[t]{5}{*}{427.7} & \multirow[t]{5}{*}{$<0.0001^{\star}$} \\
\hline Poorer & $2252(18.7)$ & 66.8 & 25.0 & 8.2 & & \\
\hline Middle & $2509(20.9)$ & 61.5 & 28.0 & 10.5 & & \\
\hline Richer & $2533(21.1)$ & 57.2 & 28.2 & 14.6 & & \\
\hline Richest & 2675 (22.2) & 49.9 & 30.9 & 19.2 & & \\
\hline \multicolumn{7}{|l|}{ Marital status } \\
\hline Single & $4191(34.9)$ & 76.8 & 17.4 & 5.8 & 120.1 & $<0.0001^{*}$ \\
\hline Currently married & $7021(58.4)$ & 52.1 & 31.9 & 16.0 & & \\
\hline Separated/divorced/widowed & $809(6.7)$ & 61.1 & 27.4 & 11.5 & & \\
\hline
\end{tabular}

Continued 
Table 2 Continued

\begin{tabular}{|c|c|c|c|c|c|c|}
\hline \multirow[b]{2}{*}{ Variable } & \multirow[b]{2}{*}{ Frequency (\%) } & \multicolumn{3}{|c|}{ Body mass index (BMI) status (\%) } & \multirow[b]{2}{*}{$x^{2}$} & \multirow[b]{2}{*}{$P$ value } \\
\hline & & $\mathrm{BMI}<23 \mathrm{~kg} / \mathrm{m}^{2}$ & $\begin{array}{l}23 \mathrm{~kg} / \mathrm{m}^{2} \geq \mathrm{BMI} \\
<27.5 \mathrm{~kg} / \mathrm{m}^{2}\end{array}$ & $\mathrm{BMI} \geq 27.5 \mathrm{~kg} / \mathrm{m}^{2}$ & & \\
\hline 0 & $5010(41.7)$ & 75.2 & 18.4 & 6.4 & 759.6 & $<0.0001^{\star}$ \\
\hline 1 & $1844(15.3)$ & 55.5 & 30.8 & 13.7 & & \\
\hline 2 & $1903(15.8)$ & 49.4 & 32.7 & 17.9 & & \\
\hline 3 & $1405(11.7)$ & 45.6 & 36.1 & 18.3 & & \\
\hline$>3$ & $1859(15.5)$ & 54.0 & 30.4 & 15.6 & & \\
\hline \multicolumn{7}{|c|}{ Number of household members } \\
\hline$\leq 5$ & $7402(61.6)$ & 59.8 & 27.2 & 13.0 & 7.4 & $<0.001^{*}$ \\
\hline$>5$ & $4620(38.4)$ & 63.9 & 25.5 & 10.6 & & \\
\hline \multicolumn{7}{|c|}{ Frequency of viewing television } \\
\hline Not at all & $2779(23.1)$ & 67.2 & 24.5 & 8.3 & 89.7 & $<0.001^{*}$ \\
\hline Less than once a week & $2015(16.8)$ & 63.3 & 25.9 & 10.8 & & \\
\hline At least once a week & $7227(60.1)$ & 58.5 & 27.5 & 14.0 & & \\
\hline
\end{tabular}

${ }^{*} p$-value $<0.05$.

frequency of television watching. This may be due to the higher coverage of electricity and the availability of many satellite channels in urban areas in comparison to rural areas. ${ }^{25}$

It was found that among rural women, the prevalence of overweight and obesity was significantly associated with watching television at least once a week. This finding is also consistent with the finding from Bangladesh. ${ }^{25}$

Despite the frequency of television watching was higher among urban women, there was no association between this behaviour and the prevalence of overweight and obesity. However, they were more likely to be overweight/ obese than rural women. A propensity towards a more sedentary lifestyle and the intake of high calorie foods by the urban residents may be potential determinants that have overridden the effect from an increased frequency of watching television. On the other hand, reliance on less

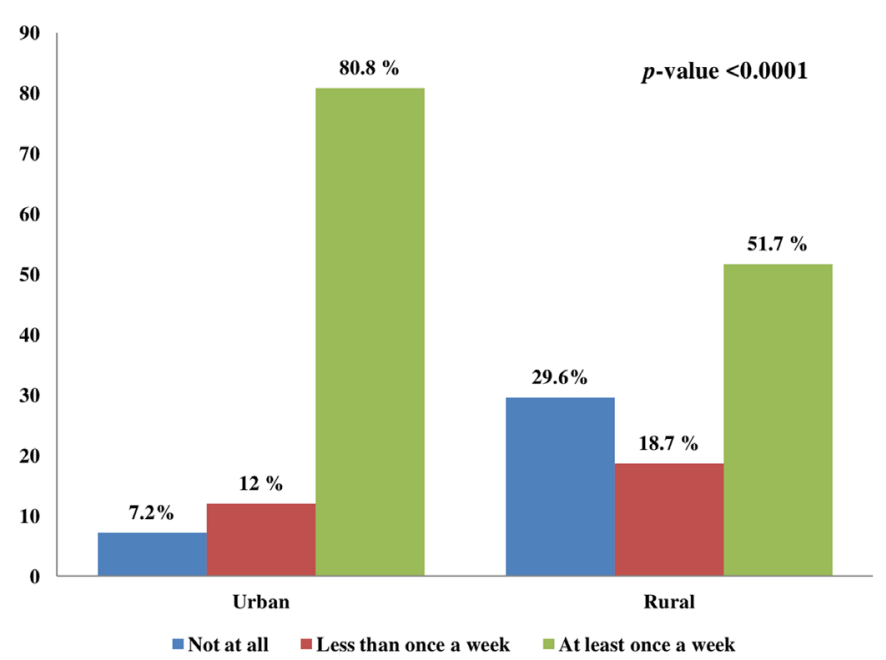

Figure 3 Distribution of the respondents by place of residence with frequency of watching television. developed transportation facilities, involvement in more laborious work and comparatively lower consumption of obesogenic diets among the rural women are factors that may contribute to a lower prevalence of overweight and obesity. ${ }^{25}$ Those who view television more frequently in the rural area are more prone to lead a sedentary lifestyle and as such are at greater risk of developing obesity. ${ }^{25}$

The findings from our study are coherent with a recent study in Bangladesh, which showed a positive association between the frequency of television viewing and overweight and obesity in women of reproductive age. ${ }^{25}$ Similar positive associations were also found in developed countries (eg, USA and Australia). ${ }^{20-24}$ In a recently published multicountry study, this association has also been observed in the case of children and adolescents. ${ }^{37}$

\section{Policy and programme implications}

The high prevalence of overweight/obesity is associated with an increased burden from NCDs in Myanmar, as shown by recent evidence. ${ }^{738}$ An unintended consequence of the continuing economic development of the country is the increasing preference for a sedentary lifestyle and obesogenic food, which, in turn, is raising the burden of overweight/obesity. Considering the epidemiological, demographic and nutritional transition, the policy makers of Myanmar should focus on the prevention and control of both overweight and obesity and NCDs. The newly released 'Myanmar National Health Plan 2017-2021' incorporates NCD prevention and control programmes ${ }^{39}$ Furthermore, a social behavioural change communication campaign should be developed in order to promote physical activity and raise awareness among the population, especially among children and adolescents, in order to prevent overweight/obesity as early as possible. Further research should be conducted among 
Table 3 Association between the frequency of viewing television and overweight and obesity among reproductive age women of Myanmar, MDHS 2015-2016

\begin{tabular}{|c|c|c|c|c|}
\hline Frequency of viewing Te & COR (95\% Cl) & $P$ value & AOR (95\% Cl) & $P$ value \\
\hline Not at all & Ref & & Ref & \\
\hline At least once a week & 1.49 (1.32 to 1.69$)$ & $<0.001^{*}$ & 1.16 (1.02 to 1.32$)$ & $0.023^{*}$ \\
\hline \multicolumn{5}{|l|}{ In urban areas } \\
\hline Less than once a week & $1.15(0.80$ to 1.67$)$ & 0.441 & $1.05(0.73$ to 1.51$)$ & 0.779 \\
\hline At least once a week & 1.25 (0.93 to 1.69$)$ & 0.144 & 1.14 (0.85 to 1.52$)$ & 0.389 \\
\hline \multicolumn{5}{|l|}{ In rural areas } \\
\hline Not at all & Ref & & Ref & \\
\hline
\end{tabular}

Results are based on ordered logistics regression and adjusted for age, place of residence, region of residence, highest educational status, current employment status, wealth index, parity and number of household members. The $\mathrm{BMI}<23 \mathrm{~kg} / \mathrm{m}^{2}$ group was held as the reference group.

AOR, adjusted OR; COR, crude OR; MDHS, Myanmar Demographic and Health Survey.

${ }^{*} p$-value $<0.05$.

men and adolescents to determine whether this positive association exists among that target population as well.

\section{STRENGTHS AND LIMITATIONS}

This is the first study, which used a nationally representative sample to examine the association between the frequency of watching television and overweight/obesity among women of reproductive age in Myanmar. Moreover, as MDHS used standard and valid tools for data collection, the probability of the existence of any measurement error is lower in this study in comparison to other cross-sectional studies conducted in Myanmar. However, the survey could not establish the temporal relationship between the exposure and the outcome variables because of its cross-sectional design. As a result, the causal association that frequent TV watching may cause obesity could not be established. The frequency of television viewing was measured in weeks, as opposed to days/hours; the latter could have given more precise information. In the multivariable analysis, food habits and duration of physical activity were not included because this information was not collected in MDHS. There may be the presence of reporting bias while measuring the frequency of television watching. The information related to the frequency of time spent on other types of telecommunication devices such as mobile phones or computers was not collected, so the association with those variables with overweight/ obesity could not be measured.

\section{CONCLUSIONS}

The rising burden of overweight and obesity is now a global concern. Obesity ultimately leads to the development of NCDs and premature death. The results from this study demonstrate that watching television is associated with obesity among reproductive age women in Myanmar. Therefore, necessary steps should be taken to improve awareness regarding the harmful consequences of watching TV for longer hours and physical inactivity as well as to encourage increased physical activity. Additional research is also warranted to explore the situation among the general population of Myanmar.

\section{Author affiliations}

${ }^{1}$ Centre for Non-Communicable Diseases and Nutrition, BRAC James P Grant School of Public Health, BRAC University, Dhaka, Bangladesh

${ }^{2}$ Centre for Science of Implementation and Scale-Up, BRAC James P Grant School of Public Health, BRAC University, Dhaka, Bangladesh

${ }^{3}$ Department of Health Services Policy and Management, Arnold School of Public Health, University of South Carolina, Columbia, South Carolina, USA

${ }^{4}$ Department of Health Promotion, Education, and Behavior, Arnold School of Public Health, University of South Carolina, Columbia, South Carolina, USA

${ }^{5}$ Institute of Public Health, University of Heidelberg, Heidelberg, Germany

Acknowledgements The authors acknowledge the DHS program for providing access to the dataset. We are also grateful to Mr. Shams Shabab Haider (Research Assistant, BRAC James P Grant School of Public Health, BRAC University) for his critical feedback in the manuscript.

Contributors RDG, IHS, MH, IS and MS conceptualised the study. RDG, IHS, MH, IS, MRH and MS designed the study and acquired the data. RDG, IHS, MH and IS conducted the data analysis. RDG, IHS, MH, IS, MRH and MS interpreted the data. RDG, IHS, MH, IS and MRH prepared the first draft. RDG, IHS, MH, IS, MRH and MS participated in critical revision of the manuscript and contributed to its intellectual improvement. All authors went through the final draft and approved it for submission. RDG, IHS, MH and IS equally contributed in this work as first authors.

Funding The authors have not received a specific grant for this research from any funding agency in the public, commercial or not-for-profit sectors.

Competing interests None declared.

Patient consent for publication Not required. 
Ethics approval MDHS received ethical approval from the Ethics Review Committee on Medical Research including Human Subjects in the Department of Medical Research, Ministry of Health and Sports as well as from the ICF Institutional Review Board.

Provenance and peer review Not commissioned; externally peer reviewed.

Data sharing statement The data set of MDHS 2015-16 is available at the Demographic and Health Surveys Program. Extra data are available on request at http://dhsprogram-com/what-we-do/survey/survey-display-349.cfm.

Open access This is an open access article distributed in accordance with the Creative Commons Attribution Non Commercial (CC BY-NC 4.0) license, which permits others to distribute, remix, adapt, build upon this work non-commercially, and license their derivative works on different terms, provided the original work is properly cited, appropriate credit is given, any changes made indicated, and the use is non-commercial. See: http://creativecommons.org/licenses/by-nc/4.0/.

\section{REFERENCES}

1. Hanson M, Gluckman P, Bustreo F. Obesity and the health of future generations. Lancet Diabetes Endocrinol 2016;4:966-7.

2. Poston L, Caleyachetty R, Cnattingius S, et al. Preconceptional and maternal obesity: epidemiology and health consequences. Lancet Diabetes Endocrinol 2016;4:1025-36.

3. Biswas T, Uddin MJ, Mamun AA, et al. Increasing prevalence of overweight and obesity in Bangladeshi women of reproductive age: Findings from 2004 to 2014. PLoS One 2017;12:e0181080.

4. Ng M, Fleming T, Robinson M, et al. Global, regional, and national prevalence of overweight and obesity in children and adults during 1980-2013: a systematic analysis for the Global Burden of Disease Study 2013. Lancet 2014;384:766-81.

5. Bonita R, Magnusson R, Bovet P, et al. Country actions to meet UN commitments on non-communicable diseases: a stepwise approach Lancet 2013;381:575-84.

6. Ministry of Health and Sports (MoHS), ICF. Myanmar Demographic and Health Survey 2015-16: final report. 2017 https://dhsprogram. com/pubs/pdf/FR324/FR324.pdf

7. Hong SA, Peltzer K, Lwin KT, et al. The prevalence of underweight, overweight and obesity and their related socio-demographic and lifestyle factors among adult women in Myanmar, 2015-16. PLoS One 2018;13:e0194454.

8. Al-Goblan AS, Al-Alfi MA, Khan MZ. Mechanism linking diabetes mellitus and obesity. Diabetes Metab Syndr Obes 2014;7:587.

9. Jiang SZ, Lu W, Zong XF, et al. Obesity and hypertension. Exp Ther Med 2016;12:2395-9.

10. Poirier P, Giles TD, Bray GA, et al. Obesity and cardiovascular disease: pathophysiology, evaluation, and effect of weight loss: an update of the 1997 American Heart Association Scientific Statement on Obesity and Heart Disease from the Obesity Committee of the Council on Nutrition, Physical Activity, and Metabolism. Circulation 2006;113:898-918.

11. Basen-Engquist $\mathrm{K}$, Chang M. Obesity and cancer risk: recent review and evidence. Curr Oncol Rep 2011;13:71-6.

12. Kovesdy CP, Furth SL, Zoccali C, et al. Obesity and kidney disease: hidden consequences of the epidemic. J Nephrol 2017;30:1-10.

13. Kanguru L, McCaw-Binns A, Bell J, et al. The burden of obesity in women of reproductive age and in pregnancy in a middle-income setting: A population based study from Jamaica. PLoS One 2017;12:e0188677.

14. Kim SY, England L, Wilson HG, et al. Percentage of gestational diabetes mellitus attributable to overweight and obesity. Am J Public Health 2010;100:1047-52.

15. Bennett GG, Wolin KY, Viswanath K, et al. Television viewing and pedometer-determined physical activity among multiethnic residents of low-income housing. Am J Public Health 2006;96:1681-5.

16. Hu FB, Li TY, Colditz GA, Fb H, Ty L, et al. Television watching and other sedentary behaviors in relation to risk of obesity and type 2 diabetes mellitus in women. JAMA 2003;289:1785-91.
17. Tuoyire DA. Television exposure and overweight/obesity among women in Ghana. BMC Obes 2018;5:8.

18. Maher C, Olds TS, Eisenmann JC, et al. Screen time is more strongly associated than physical activity with overweight and obesity in 9- to 16-year-old Australians. Acta Paediatr 2012;101:1170-4.

19. Rey-López JP, Vicente-Rodríguez G, Biosca M, et al. Sedentary behaviour and obesity development in children and adolescents. Nutr Metab Cardiovasc Dis 2008;18:242-51.

20. Cleland VJ, Schmidt MD, Dwyer T, et al. Television viewing and abdominal obesity in young adults: is the association mediated by food and beverage consumption during viewing time or reduced leisure-time physical activity? Am J Clin Nutr 2008;87:1148-55.

21. Ghavamzadeh S, Khalkhali HR, Alizadeh M. TV viewing, independent of physical activity and obesogenic foods, increases overweight and obesity in adolescents. J Health Popul Nutr 2013;31:334-42.

22. Chen C-Y, Pereira MA, Kim KH, et al. Fifteen-Year Prospective Analysis of Television Viewing and Adiposity in African American and Caucasian Men and Women. Sage Open 2015;5:215824401560048.

23. He K, Hu FB, Colditz GA, et al. Changes in intake of fruits and vegetables in relation to risk of obesity and weight gain among middle-aged women. Int J Obes Relat Metab Disord 2004;28:1569-74.

24. Tucker LA, Bagwell M. Television viewing and obesity in adult females. Am J Public Health 1991;81:908-11.

25. Ghose B. Frequency of TV viewing and prevalence of overweight and obesity among adult women in Bangladesh: a cross-sectional study. BMJ Open 2017;7:e014399.

26. The 2014 Myanmar population and housing census. Yangon, Myanmar: Department of Population, Ministry of Labour, Immigration and Population, Myanmar. 2014.

27. Asia Pacific Observatory on health systmes and policies. The republic of the union of Myanmar: Health system review. $2014 \mathrm{http}: / /$ iris.wpro.who.int/bitstream/handle/10665.1/11354/9789290616665_ eng.pdf

28. The World Bank in Myanmar. Overview. http://www.worldbank.org/ en/country/myanmar/overview. (Accessed 6 July 2018).

29. Who EC. WHO Expert Consultation. Appropriate body-mass index for Asian populations and its implications for policy and intervention strategies. Lancet 2004;363:157-63.

30. Maldonado G, Greenland S. Simulation study of confounderselection strategies. Am J Epidemiol 1993;138:923-36.

31. Kutner M, Nachtsheim C, Neter J. Applied Linear Statistical Models. 4th edn. Irwin: McGraw-Hill, 2004.

32. Rawal LB, Kanda K, Mahumud RA, et al. Prevalence of underweight, overweight and obesity and their associated risk factors in Nepalese adults: Data from a Nationwide Survey, 2016. PLoS One 2018;13:e0205912.

33. Janjua NZ, Mahmood B, Bhatti JA, et al. Association of Household and Community Socioeconomic Position and Urbanicity with Underweight and Overweight among Women in Pakistan. PLoS One 2015;10:e0122314.

34. Ziraba AK, Fotso JC, Ochako R. Overweight and obesity in urban Africa: A problem of the rich or the poor? BMC Public Health 2009;9:465

35. Gaur K, Keshri K, Joe W. Does living in slums or non-slums influence women's nutritional status? Evidence from Indian mega-cities. Soc Sci Med 2013;77:137-46.

36. Ofori-Asenso R, Agyeman AA, Laar A, et al. Overweight and obesity epidemic in Ghana-a systematic review and meta-analysis. BMC Public Health 2016;16:1239.

37. Braithwaite I, Stewart AW, Hancox RJ, et al. The Worldwide Association between Television Viewing and Obesity in Children and Adolescents: Cross Sectional Study. PLoS One 2013;8:e74263.

38. Ministry of Health and Sports, WHO, World Diabetes Foundation. Report on National Survey of Diabetes Mellitus and Risk Factors of Non-communicable Diseases in Myanmar, 2014. http://www.who.int/ ncds/surveillance/steps/Myanmar_2014 STEPS Report.pdf

39. Ministry of Health and Sports. Myanmar National Health Plan $2017-$ 2021. 2016 http://www.nationalplanningcycles.org/sites/default/files/ planning_cycle_repository/myanmar/myanmar_national_health_plan 2017-2021_eng_.pdf 